\title{
Sexual Behaviour and Determinants of Reproductive Health Services Utilization Among Young People in a Rural Nigerian Community
}

\author{
Ajibola Idowu ${ }^{1, ~ *, ~ O l u s e y i ~ K i k e l o m o ~ I s r a e l ~}{ }^{1}$, Roseline Oluyemisi Akande ${ }^{1}$, Olatayo Ayodele Aremu ${ }^{1}$, \\ Yetunde Toyin Olasinde ${ }^{2}$ \\ ${ }^{1}$ Department of Community Medicine, Bowen University, Iwo, Nigeria \\ ${ }^{2}$ Paediatric Department, Bowen University Teaching Hospital, Ogbomoso, Nigeria
}

Email address:

idajibola@yahoo.com (A. Idowu),drssk2003@yahoo.co.uk (O. K. Israel), rossmodupe@yahoo.com (R. O. Akande), drcapotee@yahoo.com (O.A. Aremu)

${ }^{*}$ Corresponding author

To cite this article:

Ajibola Idowu, Oluseyi Kikelomo Israel, Roseline Oluyemisi Akande, Olatayo Ayodele Aremu, Yetunde Toyin Olasinde. Sexual Behaviour and Determinants of Reproductive Health Services Utilization Among Young People in a Rural Nigerian Community. Central African Journal of Public Health. Vol. 7, No. 4, 2021, pp. 204-214. doi: 10.11648/j.cajph.20210704.19

Received: July 15, 2021; Accepted: July 23, 2021; Published: August 9, 2021

\begin{abstract}
Background: Adolescents in West Africa face humungous sexual and reproductive health (SRH) challenges unlike their counterparts in developed countries. It is thus, important to contextually understand some of the factors influencing uptake of SRH services among young people in a low resource setting. Objectives: This study assessed sexual behaviour and predictors of SRH-services access and utilization of youths in Ejigbo, Osun-State, Nigeria. Methods: Crosssectional design was used and multi-stage sampling method deployed in recruiting 430 study participants. Data were collected using pretested, semi-structured, interviewer-administered questionnaire. Summary statistics were done using proporption, mean and standard deviation. Inferential statistics were done using chi-squared test and binary logistic regression at $p \leq 0.05$. Results: Mean age $( \pm \mathrm{SD})$ of the respondents was $19.07 \pm 2.78,54.1 \%$ of them were males while $56.8 \%$ were schooling as at the time of the survey. More than a quarter $(38.6 \%)$ of the respondents were sexually active prior to the survey and $14.6 \%$ of the recent sexual encounters were forced/coerced. While $25.2 \%$ had multiple sexual partners, only $43.0 \%$ used contraception (mainly condom) in their recent sexual experiences. The predictors of contraceptive (hence SRHservice) use were respondents' schooling status $(\mathrm{OR}=5.45,95 \% \mathrm{CI}=1.26-4.388)$, living situation $(\mathrm{OR}=0.430,95 \% \mathrm{CI}=1.960$ $3.8111)$ and demand for SRH services in the last clinic visits $(\mathrm{OR}=2.976,95 \% \mathrm{CI}=1.960-7.848)$. Conclusion: There was high prevalence of risky sexual behaviour and low SRH service utilization in the study setting. Nigerian government and its development partners need to be more proactive at ensuring universal access and utilization of SRH-services particularly to young people in the rural areas.
\end{abstract}

Keywords: Contraceptives, Adolescents, Youths, Young People, Sexual Behavior

\section{Introduction}

Globally, the Sexual and Reproductive Health (SRH) concerns of the young people (aged 10-24years) are of public health importance. Young people include the adolescents (1019 year old) and the youths (15-24 year old people) [1]. Interestingly, our world today has the highest percentage of young people in history as 1.8 billion people are in this age category (constituting about $27 \%$ of the global population) [1].
Moreover, an estimated 1.2 billion people are persons aged 1019 years (adolescents), accounting for 16\% of the world's population [2]. Majority of these young people are found in developing countries like Nigeria which has a 2020 projected population of over 200 million people [3]. Recent data shows that $63.3 \%$ of Nigerians are below 25 years of age with adolescents constituting about $22.5 \%$ of the population [4].

Since the 1994 International Conference on Population and Developments (ICPD) [5], SRH concerns of young 
persons have received the much-needed attention particularly in most developed countries. Yet, SRH services to young people is still rudimentary in most developing countries in spite of the demographic and socio-economic significance of this group of people. Poor or lack of attention to the SRH concerns of the young people could have dire consequences on the future socio-economic indices of their respective countries [1].

In most West African (WA) countries, Adolescent Sexual and Reproductive Health (ASRH) is still facing humungous challenges and services are either not available, accessible, affordable, acceptable or not accommodative enough. A review of literature by Melesse et al. (2020), revealed an obvious inequity in distribution of ASRH services in sub-Saharan countries [6]. Also, a 2015 WHO report shows that a vast majority of adolescents in African region have no access to Comprehensive Sexuality Education (CSE) [7]. These factors among others could be responsible for the high rates of unwanted pregnancies and child marriage in the African region and in WA precisely. Many girls in WA of which Nigeria is key, are forced into marriages in leu of quality education, making them to have reduced economic powers to negotiate sex and demand for needed SRH services [7]. It also forces many young girls to engage in transactional and intergenerational sexual relationships with weakened sex and contraceptive negotiation powers thereby increasing their vulnerability to sexually transmitted diseases (including HIV) and unplanned pregnancies [8].

Globally, about 16 million adolescents give birth yearly and almost three-quarters of adolescent pregnancies is recorded in developing countries [9]. The WHO recently estimated that at least 10 million unintended pregnancies are reported among girls aged 15-19 years in developing countries each year [10]. Moreover, a 2018 UNICEF data shows that whereas the global adolescent birth rate was 44 birth/1000 livebirths, this figure stood at 115/1000 livebirths for West and Central Africa, making the region to have the highest adolescent birth rate globally [11]. Yet, pregnancy/childbirth is currently the leading cause (39.7\%) of deaths among Nigerian adolescent girls [12]. Also, one of the dire consequences of adolescent pregnancy and child marriage in a country is low school enrolments rate and high school dropout rate. Today, more than one-in-five out-ofschool children anywhere in the world are found in Nigeria and only $67 \%$ eligible children are enrolled in primary education across the country as of 2018 [13]. Girls are disproportionately affected in terms of school enrolments as only $41 \%$ of girls in the north-east and $47 \%$ in the northwest are currently receiving primary education [13].

Lack of access to good quality SRH services and continuation of some harmful traditional practices are a contravention of several treaties such as the Convention on Elimination of All Forms of Discrimination Against Women (CEDAW, 1987) [6], ICPD resolutions, the Beijing and Maputo Plans of Actions [14-16]. Thus, realization of the
Sustainable Development Goal-3 may be elusive in Nigeria if deliberate actions are not taken [17].

Meanwhile, Nigeria was one of the first African countries to introduce CSE into the national school curricular. The country was also among the first African nations to formulate the national adolescent reproductive health policies and strategies. In spite of these government's efforts since ICPD 1994, access to and utilization of SRH services have remained low in Nigeria. Also, SRH indices for young people have remained appalling particularly in most rural communities of the country [12, 18]. For instance, the contraceptive prevalence rate (CPR) for any method was estimated at $17 \%$ and unmet contraceptive need was estimated at $48 \%$ among unmarried women in the 2018 Nigeria DHS report [12]. The report also shows that $19 \%$ of adolescent girls aged 15-19 years have begun childbearing while $14 \%$ of them had given birth as at the time of the survey [12]. Similarly, a 2015 Guttmacher Institute's report revealed the rate of induced abortion among Nigerian women aged 15-45 years to be as high as 33 per 1,000 women [19]. The report also revealed that about 212,000 Nigerian women were treated for complications of unsafe abortion in the same year [19]. Meanwhile, a recent study revealed that complications of abortion account for about $5.7 \%$ of maternal deaths in Southwest Nigeria [20]. Many of these unsafe abortions occur among young girls. A large percentage of Nigerian girls/women clandestinely opt for unsafe abortions as a result of the restrictive abortion laws in the country as safe abortion care can only be provided to save the life of the mother.

These poor SRH indices for young Nigerians underscore the need for more innovative research as there is currently dearth of comprehensive information on sexual behaviour and barriers to accessing SRH services particularly by young people in rural Nigeria. The objective of this study was thus to elucidate on young people's sexuality, their access to and utilization of SRH services in a resource-poor setting. Information generated from this study can guide in the design of cost-effective SRH policies and interventions for young Nigerians.

\section{Materials and Methods}

Study setting and design: This cross-sectional study was conducted within Ejigbo community which is the administrative headquarters of Ejigbo Local Government Area (LGA) of Osun State Nigeria. The 2017 projected population for Ejigbo was about 182,500 according to the Nigeria Bureau of Statistics. Yoruba is the dominant ethnic group in Ejigbo. Most inhabitants are peasant farmers but a sizable proportion of them are civil servants while others engage in trading activities which often make them to travel to other Francophone West African countries.

Inclusion/exclusion criteria: Schooling and out-of-school youths aged 15-24 years, who have been resident in the community for at least 6 months and who gave assents/consents were included in the study. Younger 
adolescents and youths who were adjudged to have illnesses which can prevent them from giving valid responses to our questions were exempted from the study.

Sample size determination: The minimum sampling size for the study was calculated using the Lesley Kish formula for estimating single proportion in a population greater than 10,000. Based on the 2018 DHS report for Nigeria, $28 \%$ of our respondents were assumed to be using contraception prior to the study [21]. A standard normal deviate of 1.96 at $95 \%$ Confidence Level and a $5 \%$ margin of error was used. A $10 \%$ non-response rate was envisaged and corrected for while the result was multiplied by 1.2 to correct for possible cluster effect. In all, a minimum sample size of 413 was estimated but 438 respondents participated in the study.

The sampling method: A cluster multi-stage sampling method was used in recruiting eligible study participants. In the first stage, Ejigbo was selected from the list of 30 LGA in Osun State by simple random method (balloting). List of existing 11 electoral wards was obtained from the LGA secretariat and two of them were chosen using simple random sampling method (balloting). All households with eligible respondents in each of the selected electoral wards were then visited for questionnaire administration. Where a household has more than one eligible respondent, one of them was chosen via simple random sampling method.

Data collection method and instrument: An intervieweradministered, semi-structured questionnaire was used for data collection. It has sections for socio-demographic characteristics of respondents, their sexual behaviour, and level of utilization of SRH services. A translation of the questionnaire into Yoruba language was made for respondents who preferred answering in their local language. Back translation was done into English language to preserve the original meanings of the questions asked. Data were collected by a group of 15 medical students trained by the principal investigator on questionnaire administration to youths in rural settings. Data were collected within three weeks in December, 2020.

Pretesting: The pretesting of the questionnaire was done in Ife-Odan community among 50 young people who were chosen by convenience sampling method. This community was not one of the ones used for the main study. The pretesting exercise helped us to strengthen the internal validity of our questionnaire. We were able to assess the adequacy of each of the questions in eliciting the desired responses from the study participants. Ambiguous questions observed were either re-phrased or completely deleted in line with the study objectives.

Data Management: Each questionnaire was edited on the field daily before the data were entered into Statistical Package for Social Sciences (IBM SPSS Statistics for Windows, version 23.0 Armonk, NY: IBM Corp.) which was used for analysis. Categorical data were summarized using percentages and presented in Tables and Charts. Continuous data were summarized using mean and standard deviation. At the bivariate level, Chi-Square test was used to compare categorical variables and the level of statistical significance was placed at $p<0.05$. A stepwise binary logistic model was built at the multivariate analysis level. Selection of variables into the model was based on whether they statistically significant at the bivariate level or if they had been previously reported in literature as significant predictor of SRH services utilization. Odds Ratio (OR) and 95\% Confidence Intervals (CI) were obtained to identified the significant predictors of SRH service utilization in the study location.

Ethical Consideration: Ethical Clearance to conduct the study was obtained from the Ethical Review Committee of the Bowen University Teaching Hospital, Ogbomoso. Also, permission was obtained from the community leader before commencing the study. Written Assents/consents were obtained from each participant and they were only allowed into the study after the research objectives were clearly explained to them. Participation in the research was entirely voluntary and participants were allowed to opt out at any stage of the interview if they so wished. Responses from the study participants were kept strictly confidential as the questionnaires were made anonymous through coding rather than use of names. Moreover, data were entered into computers which were only accessible to the principal investigators. The study inflicted no harm on the study participants and there was no need for compensation.

\section{Results}

Out of the administered 450 questionnaires, 438 were returned satisfactorily completed (97.3\% response rate). Mean $( \pm \mathrm{SD})$ age of the respondents was $19.07 \pm 2.78$ years. More than half $(59.9 \%)$ of the respondents were 15-19 years of age but only $56.8 \%$ of them were schooling as at the time of the survey. While $54.1 \%$ of the respondents were males, almost all (99.1\%) were of Yoruba ethnic group. Almost three-quarter $(73.5 \%)$ of the respondents were Muslims, three-quarter of them (75.6\%) attained secondary education. Half $(50.5 \%)$ of the respondents had mothers with secondary education and $29.4 \%$ of the respondents were employed. Majority $(90.0 \%)$ of the respondents were never married while $43.2 \%$ were living with both parents (Table 1). The most prevalent sources of SRH information were friends $(33.3 \%)$ and parents $(26.7 \%)$, respectively (Figure 1).

Table 2 shows that $38.6 \%$ of the respondents have had sexual experiences prior to the survey. Majority (62.3\%) of the sexually active respondents had their sexual debuts when they were $15-19$ years of age but $11.1 \%$ of the first sexual encounters were forced or coerced. Not less than $43.3 \%$ of the sexually active respondents stated they had more than one sexual partner with $53.8 \%$ having at least two lifetime partners. While $91.8 \%$ of the sexually active respondents engaged in heterosexual activities, $6.2 \%$ were bisexual while $1.8 \%$ were homosexual. 


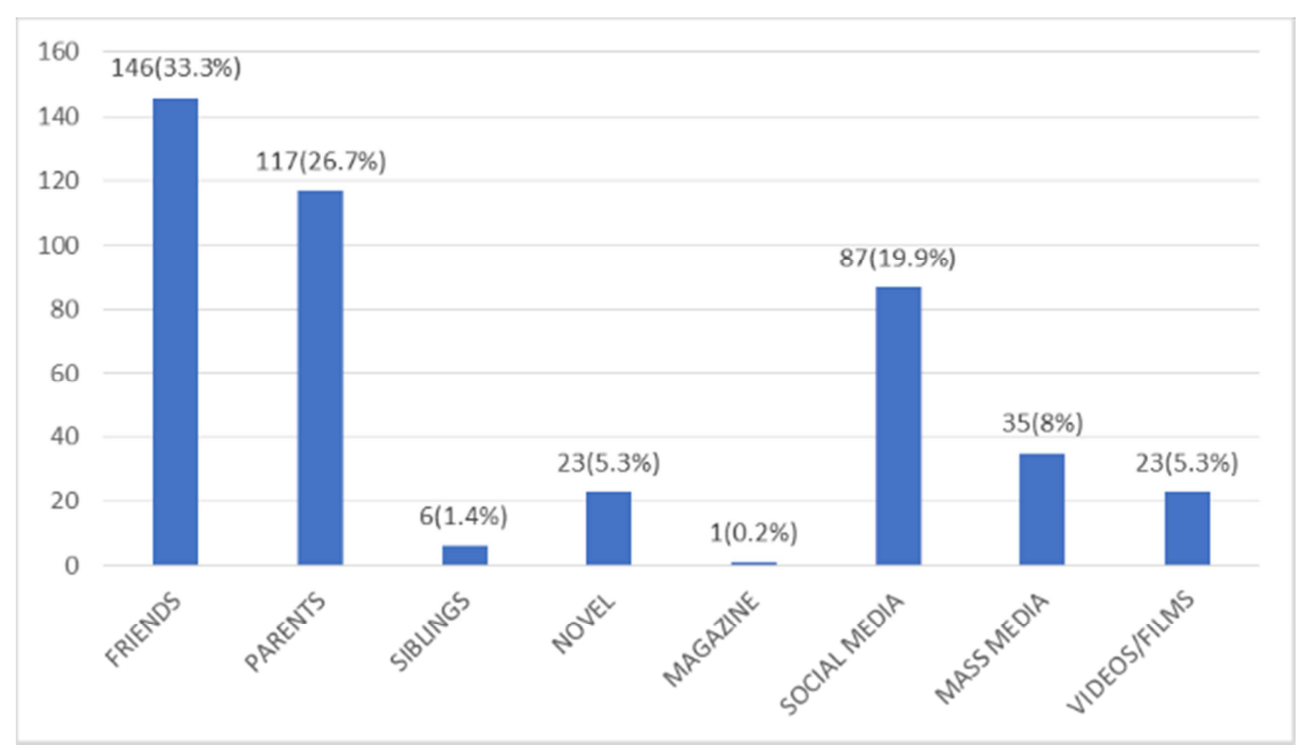

Figure 1. Respondents' sources of information on SRH.

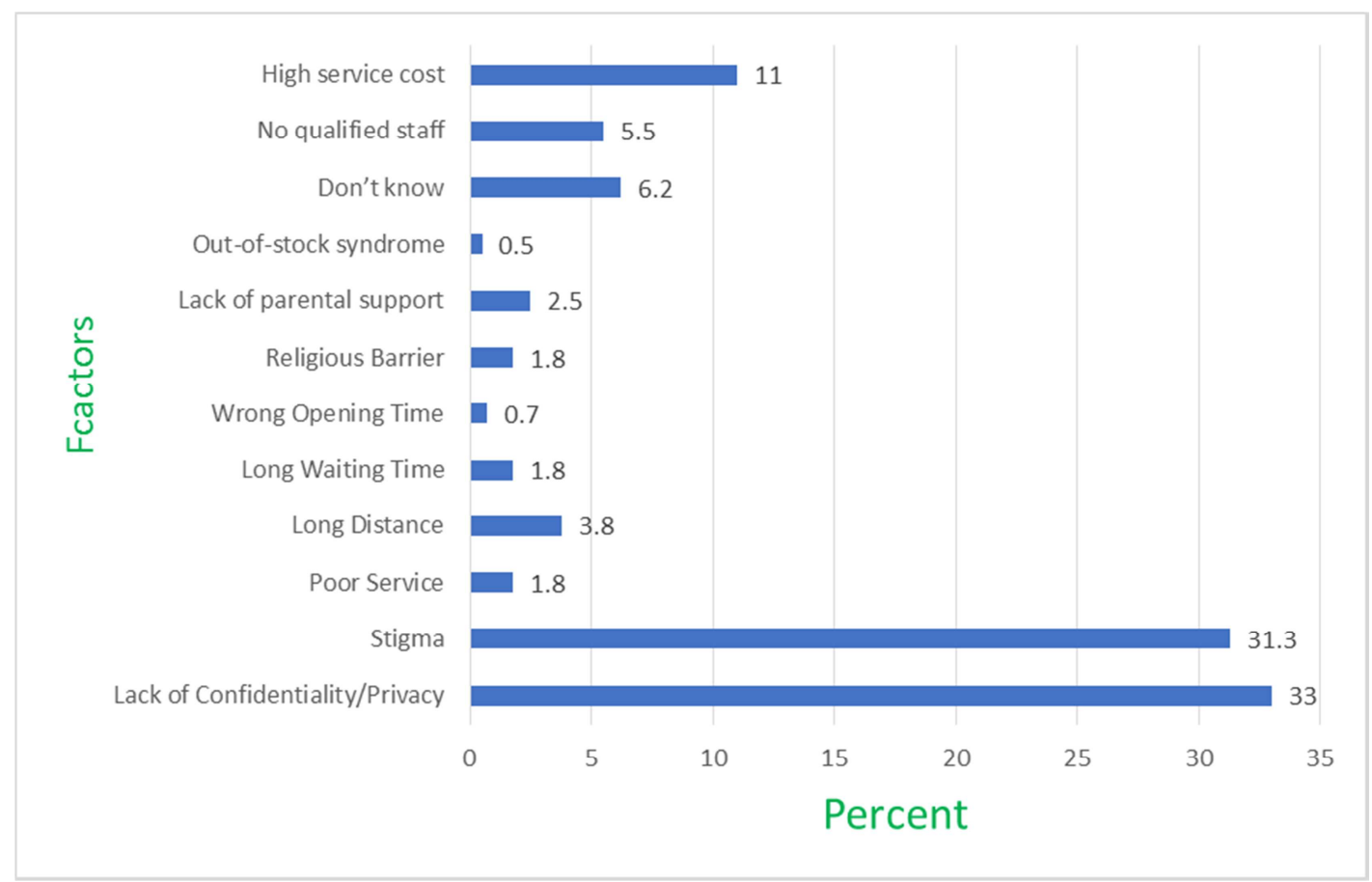

Figure 2. Respondents' perceived hindrances to SRH services utilization in the study population.

In Table $3,22.2 \%$ of the sexually active respondents had frequent sexual experiences of which $30.7 \%$ of the sexual encounters occurred within a week prior to the survey. Not less than $14.6 \%$ of the recent sexual experiences were forced and $88.8 \%$ were heterosexual in nature. Of the sexually active respondents, $25.2 \%$ currently have at least two sexual partners. Drugs were used to enhance sexual performances in $14.2 \%$ of the most recent sexual experiences and alcohol constituted $87.5 \%$ of the performance enhancing drug used. Almost half (45.4\%) of the respondents were not aware of the available SRH services in their communities while only $30.8 \%$ of them were aware of contraceptive services. A quarter $(25.6 \%)$ of the respondents stated they had sought SRH services in the healthcare facilities in the past, $55.4 \%$ of such respondents had sought care up to three times in the past one year. Of the SRH-service seekers, 55.4\% received contraceptive counselling and $42.9 \%$ demanded for contraceptive services in the last clinic attendances. In all, only $43.0 \%$ of the sexually active respondents used contraceptives in their recent sexual encounters of which condom was the most prevalent method $(81.9 \%)$. Above three-quarter $(87.5 \%)$ of the SRH-service seekers stated they were confident enough to ask SRH-related questions and $60.3 \%$ of such respondents got satisfactory answers to their questions. More than half $(56.3 \%)$ of service users felt there was no enough privacy in delivering SRH services to them and only $54.0 \%$ were assured of confidentiality of the information obtained from them. 
Table 1. Socio-demographic Characteristics of respondents.

\begin{tabular}{|c|c|c|}
\hline Variable & Frequency, $N=438$ & Percent (\%) \\
\hline \multicolumn{3}{|l|}{ Age (years) } \\
\hline$<15$ & 4 & 0.9 \\
\hline $15-19$ & 260 & 59.9 \\
\hline $20-24$ & 171 & 39.0 \\
\hline$\geq 25$ & 3 & 0.2 \\
\hline Means (SD) & $19.07 \pm 2.78$ & \\
\hline \multicolumn{3}{|l|}{ Schooling status } \\
\hline In-school & 249 & 56.8 \\
\hline Out-of-school & 189 & 43.2 \\
\hline \multicolumn{3}{|l|}{ Sex } \\
\hline Male & 237 & 54.1 \\
\hline Female & 201 & 45.9 \\
\hline \multicolumn{3}{|l|}{ Tribe } \\
\hline Yoruba & 434 & 99.1 \\
\hline Hausa & 0 & 0.0 \\
\hline Igbo & 4 & 0.9 \\
\hline \multicolumn{3}{|l|}{ Religion } \\
\hline Islam & 322 & 73.5 \\
\hline Christianity & 105 & 24.0 \\
\hline Traditional & 11 & 2.5 \\
\hline \multicolumn{3}{|l|}{ Level of Education } \\
\hline None & 8 & 1.8 \\
\hline Primary & 23 & 5.2 \\
\hline Secondary & 331 & 75.6 \\
\hline Tertiary & 76 & 17.4 \\
\hline \multicolumn{3}{|l|}{ Mother's Education } \\
\hline None & 93 & 21.2 \\
\hline Primary & 59 & 13.5 \\
\hline Secondary & 221 & 50.5 \\
\hline Tertiary & 65 & 14.8 \\
\hline \multicolumn{3}{|l|}{ Employment status } \\
\hline Student & 264 & 60.3 \\
\hline Employed & 129 & 29.4 \\
\hline Unemployed & 45 & 10.3 \\
\hline \multicolumn{3}{|l|}{ Marital status } \\
\hline Never married & 394 & 90.0 \\
\hline Cohabiting & 6 & 1.4 \\
\hline Married & 37 & 8.4 \\
\hline Separated & 1 & 0.2 \\
\hline Divorced & 0 & 0.0 \\
\hline Widowed & 0 & 0.0 \\
\hline \multicolumn{3}{|l|}{ Living situation } \\
\hline Living alone & 79 & 18.0 \\
\hline Living with friend & 12 & 2.7 \\
\hline Living with single parent & 120 & 27.4 \\
\hline Living with both parents & 189 & 43.2 \\
\hline Living with relatives & 25 & 5.7 \\
\hline Others & 13 & 3.0 \\
\hline
\end{tabular}

Table 2. Respondents' First Sexual Experiences.

\begin{tabular}{|c|c|c|}
\hline Variable & Frequency & Percent \\
\hline \multicolumn{3}{|l|}{ Ever had sex } \\
\hline Yes & 169 & 38.6 \\
\hline No & 269 & 61.4 \\
\hline Age at first sexual encounter (Years) & $\mathrm{n}=169$ & \\
\hline $10-14$ & 16 & 9.4 \\
\hline $15-19$ & 105 & 62.3 \\
\hline $20-24$ & 46 & 27.1 \\
\hline Can't remember & 2 & 1.2 \\
\hline \multicolumn{3}{|l|}{ Nature of first sexual experience } \\
\hline Forced & 19 & 11.1 \\
\hline Consensual & 150 & 88.9 \\
\hline \multicolumn{3}{|l|}{ History of multiple sexual partner } \\
\hline Yes & 73 & 43.3 \\
\hline
\end{tabular}




\begin{tabular}{lll}
\hline Variable & Frequency & Percent \\
\hline No & 96 & 56.7 \\
Number of lifetime sexual partner & 29 & 17.2 \\
1 & 49 & 29.0 \\
2 & 91 & 53.8 \\
$\geq 2$ & & \\
Types of first sexual experience & 155 & 91.8 \\
Heterosexual & 11 & 6.5 \\
Homosexual & 3 & 1.8 \\
Bisexual & & 39.5 \\
Use of contraception at first sexual encounter & 67 & 60.5 \\
Yes & 102 & \\
No & & \\
Types of Contraception used in the first sexual encounter & & \\
Emergency contraception & &
\end{tabular}

Table 3. Respondents' current/most recent sexual experiences and SRH services utilization.

\begin{tabular}{|c|c|c|}
\hline Variables & Frequency & Percent (\%) \\
\hline \multicolumn{3}{|l|}{ Frequency of sexual activities } \\
\hline Rarely & 53 & 31.0 \\
\hline Seldomly & 78 & 46.8 \\
\hline Frequently & 38 & 22.2 \\
\hline \multicolumn{3}{|l|}{ Most recent sexual experience } \\
\hline Within a week & 52 & 30.7 \\
\hline Within a month & 59 & 35.0 \\
\hline Within a year & 58 & 34.3 \\
\hline \multicolumn{3}{|l|}{ Nature of the most recent sexual experience } \\
\hline Forced & 25 & 14.6 \\
\hline Consensual & 144 & 84.4 \\
\hline \multicolumn{3}{|l|}{ Types of most recent sexual relation } \\
\hline Heterosexual & 150 & 88.8 \\
\hline Homosexual & 14 & 8.3 \\
\hline Bisexual & 5 & 3.0 \\
\hline \multicolumn{3}{|l|}{ Contraceptives used in the most recent sexual experience } \\
\hline Yes & 73 & 43.2 \\
\hline No & 96 & 56.8 \\
\hline Types of contraceptives used & $\mathrm{n}=73$ & \\
\hline Emergency contraception & 7 & 9.7 \\
\hline Herbal medicine & 6 & 8.3 \\
\hline Condom & 60 & 81.9 \\
\hline Number of current sexual partners & $\mathrm{n}=169$ & \\
\hline None & 35 & 21.6 \\
\hline 1 & 91 & 53.2 \\
\hline$\geq 2$ & 43 & 25.2 \\
\hline \multicolumn{3}{|l|}{ Used drugs to enhance the last sexual encounter } \\
\hline Yes & 24 & 14.2 \\
\hline No & 145 & 85.8 \\
\hline Types of drug used & $\mathrm{n}=24$ & \\
\hline Alcohol & 21 & 87.5 \\
\hline Marijuana & 1 & 4.2 \\
\hline Cocaine & 0 & 0.0 \\
\hline Heroin & 0 & 0.0 \\
\hline Tramadol & 0 & 0.0 \\
\hline Others & 2 & 8.3 \\
\hline Perceived available SRH services & $\mathrm{N}=438$ & Multiple responses \\
\hline Family planning counselling and services & 135 & 30.8 \\
\hline Safe abortion care & 67 & 15.3 \\
\hline HIV counselling and services & 175 & 39.9 \\
\hline STD diagnosis and care & 129 & 29.4 \\
\hline Pregnancy test and care & 131 & 29.9 \\
\hline Don't know & 188 & 45.4 \\
\hline \multicolumn{3}{|c|}{ Ever visited health facilities for to receive services or information on contraception, pregnancy, abortion or sexually transmitted diseases? } \\
\hline Yes & 112 & 25.6 \\
\hline No & 326 & 74.4 \\
\hline Number of times information was sought from a doctor or a nurse for SRH services in the last twelve months & $\mathrm{n}=112$ & \\
\hline $1-3$ & 61 & 54.5 \\
\hline $4-5$ & 24 & 21.4 \\
\hline
\end{tabular}




\begin{tabular}{|c|c|c|}
\hline Variables & Frequency & Percent $(\%)$ \\
\hline$\geq 5$ & 27 & 24.1 \\
\hline \multicolumn{3}{|l|}{ Types of clinic visited } \\
\hline Private & 71 & 63.4 \\
\hline Government & 41 & 36.6 \\
\hline \multicolumn{3}{|l|}{ Clinic distance } \\
\hline Within 5 minutes & 34 & 30.4 \\
\hline Within 30 minutes & 52 & 46.4 \\
\hline More than 30 minutes & 26 & 23.2 \\
\hline \multicolumn{3}{|l|}{ Posters on SRH sighted at the healthcare facility } \\
\hline Yes & 61 & 54.5 \\
\hline No & 51 & 45.5 \\
\hline \multicolumn{3}{|l|}{ Received talks on contraception } \\
\hline Yes & 62 & 55.4 \\
\hline No & 50 & 44.6 \\
\hline \multicolumn{3}{|c|}{ Requested for contraceptive services in the last clinic visits } \\
\hline Yes & 48 & 42.9 \\
\hline No & 64 & 57.1 \\
\hline \multicolumn{3}{|l|}{ Felt comfortable enough to ask SRH questions } \\
\hline Yes & 98 & 87.5 \\
\hline No & 14 & 12.5 \\
\hline Satisfactory answers received on questions asked & $\mathrm{N}=98$ & \\
\hline Yes & 62 & 60.3 \\
\hline No & 36 & 37.9 \\
\hline \multicolumn{3}{|c|}{ Perceived privacy to share information during consultation } \\
\hline Enough privacy & 49 & 43.7 \\
\hline No privacy & 63 & 56.3 \\
\hline \multicolumn{3}{|c|}{ Assured of confidentiality of information shared with $\mathrm{HCW}$} \\
\hline Yes & 61 & 54.0 \\
\hline No & 51 & 46.0 \\
\hline
\end{tabular}

The most predominant perceived hindrances to SRH-service access in the study population was lack of confidentiality/privacy of service deliveries and stigmatization of adolescents seeking care. These were reported by $33.0 \%$ and $31.3 \%$ of the respondents, respectively. High service cost was stated as a barrier by $11.0 \%$ of the respondents while lack of parental support accounted for $2.5 \%$ of the barrier factors (Figure 2).

Table 4 shows that in-school respondents constituted significantly higher proportion $(55.3 \%)$ of those who used contraception in the last sexual encounters $(\mathrm{p}=0.001)$. Additionally, educated respondents constituted significantly higher percentage $(42.5 \%)$ of the contraceptive users $(\mathrm{p}=0.002)$. Respondents who were living alone had significantly lower percentage $(38.0 \%)$ of contraceptive users when compared with youths with other living arrangements $(\mathrm{p}=0.023)$. Those who demanded for SRH services in the last clinic visits constituted significant higher percentage $(67.7 \%)$ of contraceptive $(\mathrm{p}=0.007)$.

At the multivariate level (Table 5), In-school respondents were 6 times more likely to use contraceptives compared to their out-of-schooling counterparts $(\mathrm{OR}=5.45 ; 95 \% \mathrm{CI}=1.264$ 4.388). Respondents who were living alone were $57 \%$ less likely to use contraceptives compared to those with other living arrangements $\quad(\mathrm{OR}=0.43 ; \quad 95 \% \mathrm{CI}=1.96-3.81)$. Respondents who requested for contraceptive services in the last clinic visits were 3 times more likely to use contraception compared to those who did not $(\mathrm{OR}=2.98 ; 95 \% \mathrm{CI}=1.14-5.66)$.

Table 4. Factors associated with contraceptive use in the last sexual experiences of the respondents.

\begin{tabular}{|c|c|c|c|c|c|}
\hline \multirow{2}{*}{ Variable } & \multicolumn{2}{|c|}{ Used contraception in the last sexual experience } & \multirow{2}{*}{ Total } & \multirow{2}{*}{$\mathbf{X}^{2}$} & \multirow{2}{*}{ p-value } \\
\hline & Yes $(\%)$ & No $(\%)$ & & & \\
\hline Age (years) & & & & 1.580 & 0.454 \\
\hline$<15$ & $1(100.0)$ & $0(0.0)$ & 1 & & \\
\hline $15-19$ & $25(40.3)$ & $37(59.7)$ & 62 & & \\
\hline $20-24$ & $47(44.3)$ & $59(55.7)$ & 106 & & \\
\hline$\geq 25$ & $0(0.0)$ & $0(0.0)$ & 0 & & \\
\hline Schooling status & & & & 6.507 & $0.011 *$ \\
\hline In-school & $41(53.9)$ & $35(46.1)$ & 76 & & \\
\hline Out-of-school & $32(34.4)$ & $61(65.6)$ & 93 & & \\
\hline Sex & & & & 11.300 & 0.057 \\
\hline Male & $59(52.2)$ & $54(47.8)$ & 113 & & \\
\hline Female & $14(25.0)$ & $42(75.0)$ & 56 & & \\
\hline Religion & & & & 2.260 & 0.323 \\
\hline Islam & $15(35.7)$ & $27(64.3)$ & 42 & & \\
\hline Christianity & $53(44.5)$ & $66(55.6)$ & 119 & & \\
\hline Traditional & $5(62.5)$ & $3(37.5)$ & 8 & & \\
\hline Level of Education & & & & 8.708 & $0.033^{*}$ \\
\hline None & $1(20.0)$ & $4(80.0)$ & 5 & & \\
\hline
\end{tabular}




\begin{tabular}{|c|c|c|c|c|c|}
\hline \multirow{2}{*}{ Variable } & \multicolumn{2}{|c|}{ Used contraception in the last sexual experience } & \multirow{2}{*}{ Total } & \multirow{2}{*}{$\mathbf{X}^{2}$} & \multirow{2}{*}{ p-value } \\
\hline & Yes (\%) & No (\%) & & & \\
\hline Primary & $3(25.0)$ & $9(75.0)$ & 12 & & \\
\hline Secondary & $44(38.6)$ & $70(61.4)$ & 114 & & \\
\hline Tertiary & $22(57.9)$ & $16(42.1)$ & 38 & & \\
\hline Mother's Education & & & & 1.304 & 0.728 \\
\hline None & $15(40.5)$ & $22(59.5)$ & 37 & & \\
\hline Primary & $18(47.4)$ & $20(52.6)$ & 38 & & \\
\hline Secondary & $31(40.3)$ & $46(59.7)$ & 77 & & \\
\hline Tertiary & $9(52.9)$ & $8(47.1)$ & 17 & & \\
\hline Living situation & & & & 12.555 & $0.028^{*}$ \\
\hline Living alone & $25(55.6)$ & $20(44.4)$ & 45 & & \\
\hline Living with friend & $3(33.3)$ & $6(66.7)$ & 9 & & \\
\hline Living with single parent & $21(53.8)$ & $18(46.2)$ & 39 & & \\
\hline Living with both parents & $19(39.6)$ & $29(60.4)$ & 48 & & \\
\hline Living with relatives & $3(18.8)$ & $13(81.3)$ & 16 & & \\
\hline Others & $2(16.7)$ & $10(83.3)$ & 12 & & \\
\hline Used drugs to enhance the last sexual encounter & & & & 1.245 & 0.265 \\
\hline Yes & $13(54.2)$ & $11(45.8)$ & 24 & & \\
\hline No & $60(42.00)$ & $83(58.0)$ & 143 & & \\
\hline $\begin{array}{l}\text { Ever visited health facilities for to receive services or } \\
\text { information on contraception, pregnancy, abortion or sexually } \\
\text { transmitted diseases? }\end{array}$ & & & & 0.001 & 0.980 \\
\hline Yes & $28(43.1)$ & $37(56.9)$ & 65 & & \\
\hline No & $45(43.3)$ & $59(56.70$ & 104 & & \\
\hline Received talks on contraception & & & & 0.372 & 0.542 \\
\hline Yes & $19(51.4)$ & $18(48.6)$ & 37 & & \\
\hline No & $15(44.1)$ & $19(55.9)$ & 34 & & \\
\hline Demanded for SRH services & & & & 4.985 & $0.026^{*}$ \\
\hline Yes & $20(62.5)$ & $12(37.5)$ & 32 & & \\
\hline No & $14(35.9)$ & $25(64.1)$ & 39 & & \\
\hline Clinic distance & & & & 5.125 & 0.077 \\
\hline Within 5 minutes & $7(31.8)$ & $15(68.2)$ & 22 & & \\
\hline Within 30 minutes & $21(60.0)$ & $14(40.0)$ & 35 & & \\
\hline More than 30 minutes & $5(35.7)$ & $9(64.3)$ & 14 & & \\
\hline
\end{tabular}

*Statistically significant at $\mathrm{P}<0.05$.

Table 5. Predictors of contraceptive use in the last sexual experiences among the respondents.

\begin{tabular}{|c|c|c|c|c|}
\hline Variable & B-Coefficient & $P$-value & Odds Ratio & $95 \%$ C I \\
\hline \multicolumn{5}{|l|}{ Schooling status } \\
\hline In-school & $\mathrm{RC}$ & $0.011 *$ & 5.45 & $1.26-4.388$ \\
\hline Out-of-school & -0.803 & & & \\
\hline \multicolumn{5}{|l|}{ Sex } \\
\hline Male & $\mathrm{RC}$ & 0.061 & 0.305 & $0.150-2.620$ \\
\hline Female & -1.187 & & & \\
\hline \multicolumn{5}{|l|}{ Level of Education } \\
\hline None & $\mathrm{RC}$ & & & \\
\hline Primary & 2.485 & 0.056 & 12.000 & $0.936-5.388$ \\
\hline Secondary & 1.851 & 0.103 & 6.364 & $0.689-8.798$ \\
\hline Tertiary & 1.068 & 0.359 & 2.909 & $0.296-8.554$ \\
\hline \multicolumn{5}{|l|}{ Living situation } \\
\hline Living alone (RC) & & $0.027 *$ & 0.430 & $1.960-3.8111$ \\
\hline Other & -1.764 & & & \\
\hline Requested for contraceptive services in the last clinic visits & & & & \\
\hline Yes & 1.091 & $0.021 *$ & 2.976 & $1.129-7.848$ \\
\hline No & RC & & & \\
\hline
\end{tabular}

*Statistically Significant $\mathrm{p}<0.05 \mathrm{RC}=$ Reference Category $\mathrm{CI}=$ Confidence Interval

\section{Discussions}

In the current study, $38.6 \%$ of the respondents have had sexual experiences prior to the survey. This finding is in keeping with results from previous studies [4, 22]. Majority of the sexually active respondents in the current study had their sexual debuts when they were 15-19 years of age. This is also in consonance with the reports from past studies $[12,23,24]$.

The current study also revealed that $11.1 \%$ and $14.6 \%$ of the first sexual and the most recent sexual encounters were forced or coerced. Recent studies have indicated increasing burden of sexual violence in Nigeria of which females are main victims $[25,26]$. Sexual assaults occur both within and 
outside the family settings, aggravated by the worsening insecurity in the country in which bandits often rape and sexually molest their female victims. Regrettably, most sexual violence cases in Nigeria go unreported due to the stigma attached to it, making many victims to silently nurture the emotional trauma over a long period. Hence, relevant agencies need to work synergistically to ensure that victims of sexual violence have enabling environment and necessary supports to disclose their ordeals. Also, there is urgent need to fully implement the 2015 Violence Against Persons Prohibition Act (VAPPA) which criminalize sexual violence in Nigeria [27].

Many of the sexually active study participants had multiple sexual partners in the current study. Also, performance enhancing drugs (mainly alcohol) was used in some of the most recent sexual activities. These indicates high rate of Risky Sexual Behaviour (RSB) among the respondents similar to what have been reported in previous studies [28-31].

Even though majority of respondents in our study were confident to talk about their SRH concerns, only half of them were assured of confidentiality of the given SRH information while less than half stated there was adequate privacy in their last clinic visits. Hence, authors recommend increased efforts by service providers to ensure that young people seeking SRH services are treated as right-owners, with dignity and confidentiality, free of stigma and discrimination. The dutybearers (governments) should ensure establishment of wellequipped youth friendly health centers at strategic locations particularly in rural areas of Nigeria to improve access to SRH services.

In the current study, contraceptives were used in less than half of the most recent sexual encounters. Moreover, only half of SRH-services seekers received contraceptive counselling while less than half of them demanded for contraceptive services in the last clinic attendances. Our findings are in concordance with what have been reported in previous studies [32, 33]. Also, the 2018 Nigeria DHS report estimated that only $28 \%$ of unmarried women use modern contraception while unmet need for modern contraception was as high as $48 \%$ among unmarried women in Nigeria. Yet, the vision of the United Nations FP2020 programme was to ensure equitable access to contraception particularly to the vulnerable groups such as the adolescents, women and those in lower socio-economic class [34]. Thus, Nigerian policy makers need to further prioritize universal access to modern contraception for the young people. Appropriate socialmarketing strategies should be deployed, and varied channels of communication utilized to ensure that accurate and reliable SRH information are made available to improve utilization of SRH services by the Nigerian youths.

Educated youths were more likely to use contraceptives in our study population. This underscores the importance of basic education in determining healthcare service utilization as youths have access to age-appropriate sexuality education. Consequently, the Nigeria governments need to invest more to ensure universal access to quality education in the country.

Respondents who were living with their parents were also more likely to use contraception compared to those living alone or with friends in the current study. Family connectedness has been reported as a strong predictor of adolescent/youth sexual behaviour with those living with parents engaging in lesser RSBs [35]. Thus, Nigerian parents need to be carried along in providing age-appropriate sexuality education to the adolescents in schools. Moreover, financial barriers to accessing SRH services by the Nigerian adolescents/youths can be eliminated by increasing budgetary allocation to health. A well-articulated Conditional Cash Transfer (CCT) and voucher systems in addition to a veritable Private-Public partnership can also be explored in trying to achieve universal SRH service coverage for the Nigerian youths. These strategies have the capacity to improve the demand and utilization of SRH services among the adolescents/youths as only those who demanded for services in their last clinic visits in the current study eventually used contraception which we used as a proxy for SRH service utilization.

Based on findings from the current study, authors call for implementation research to assess the impacts of existing interventions aiming at improving access to Youth Friendly Health Services in Nigeria. With this, identified impactful programmes can be reenergized or replicated for greater results while the less effective ones are either replanned or deemphasized. Moreover, there is need for qualitative research to fully understand the socio-cultural factors influencing uptake of SRH services among Nigerian youths in rural areas.

Study Limitation

The results from this study may have been affected by social-desirability bias in which respondents may have given responses which they believed may be of interest to the investigators. The fact that cluster-effect was corrected for and a sufficient sample size used may have minimized the effects of this bias.

\section{Conclusion}

There is preponderance of risky sexual activities and suboptimal SRH services utilization among youths in the study population. Lack of confidentiality and stigmatization were the perceived hindrances to SRH use among the respondents. School-going respondents, those living with parents and those who demanded for care were more likely to use SRH services. The Nigerian governments need to be more proactive in making equitable SRH services universally accessible to the young people who are living in the rural areas.

\section{Authors Contributions}

AI conceptualize the research Idea and drafted the manuscript, OKI reviewed the manuscript for important intellectual contents, ROA supervised data collection and analysis, OAA reviewed the article for important intellectual contents. All authors gave approvals for publication of the final draft. 


\section{Conflict of Interest Statement}

The authors declare that they have no competing interests.

\section{Acknowledgements}

Authors wish to acknowledge the medical students of Bowen University, Iwo Nigeria who assisted in data collection and the good people of Ejigbo community where the study took place.

\section{References}

[1] Das Gupta M, Engelman R, Levy J, Luchsinger G, Merrick T, Rosen JE, et al. The State of World Population 2014 RESEARCHERS AND AUTHORS Other contributions from Sarah Castle UNFPA ADVISORY TEAM. 2014. [cited 2021 Jun 1]. Available from: https://www.unfpa.org/sites/default/files/pub-pdf/ENSWOP14-Report_FINAL-web.pdf.

[2] UNICEF. Adolescents Statistics - UNICEF DATA. [cited 2021 Feb 10]. Available from: https://data.unicef.org/topic/adolescents/overview/.

[3] Worldometer. Nigeria Population (2020) - Worldometer. [cited 2021 Apr 4]. Available from: https://www.worldometers.info/world-population/nigeriapopulation/.

[4] Cortez R, Saadat S, Marinda E, Oluwole O. Adolescent sexual and reproductive health in Nigeria. 2015. p. 1-4. [cited 2021 June 1]. Available from: https://openknowledge.worldbank.org/handle/10986/21626.

[5] ICPD. International Conference on Population and Development (ICPD) | UNFPA - United Nations Population Fund [Internet]. [cited 2021 Mar 4]. Available from: https://www.unfpa.org/events/international-conferencepopulation-and-development-icpd.

[6] Melesse DY, Mutua MK, Choudhury A, Wado YD, Faye CM, Neal S, et al. Adolescent sexual and reproductive health in sub-Saharan Africa: who is left behind? Analysis. BMJ Glob Heal. 2020; 5: 2231. doi: 10.1136/bmjgh-2019-002231.

[7] WHO. Visualising the problems and generating solutions for Adolescent Health in Africa Region. [cited 2021 Feb 20]. Available from: moz-extension: //d51209c7-e71a-4235-910ff13d2c182273/enhancedreader.html?openApp\&pdf=https $\% 3 \mathrm{~A} \% 2 \mathrm{~F} \% 2 \mathrm{Fwww}$.afro.who .int $\% 2$ Fsites $\% 2$ Fdefault $\% 2$ Ffiles $\% 2$ F $2018-05 \% 2 F A S R H-$ $\% 2520$ AFRO $\% 2520$ -

$\% 2520 \mathrm{AH} \% 2520$ workshop\%2520report.pdf.

[8] Stoebenau K, Heise L, Wamoyi J, Bobrova N. Revisiting the understanding of "transactional sex" in sub-Saharan Africa: A review and synthesis of the literature. Vol. 168, Social Science and Medicine. Elsevier Ltd; 2016. p. 186-97.

[9] UNFPA. GIRLHOOD, NOT MOTHERHOOD Preventing Adolescent Pregnancy. 2015. [cited 2021 May 22]. Available from: https://www.unfpa.org/sites/default/files/pubpdf/Girlhood_not_motherhood_final_web.pdf.

[10] WHO. Adolescent pregnancy. [cited Mar 1]. Available from: https://www.who.int/en/news-room/fact- sheets/detail/adolescent-pregnancy.

[11] UNICEF DATA. Early childbearing - UNICEF DATA. [cited 2021 Jan 14]. Available from: https://data.unicef.org/topic/child-health/adolescent-health/.

[12] National Population Commission, Abuja, Nigeria and ICF Rockville MU. The Federal Republic of Nigeria Nigeria Demographic and Health Survey 2018 National Population Commission Abuja, Nigeria. 2019.

[13] UNICEF. Situation of women and children in Nigeria UNICEF Nigeria. [cited 2021 Jan 27]. Available from: https://www.unicef.org/nigeria/situation-women-and-childrennigeria.

[14] UNFPA. International Conference on Population and Development (ICPD) | UNFPA - United Nations Population Fund. [cited 2021 Feb 8]. Available from: https://www.unfpa.org/events/international-conferencepopulation-and-development-icpd.

[15] United Nations. United Nations Report of the Fourth World Conference on Women Beijing, 4-15 September 1995. [cited 2021 Feb 2]. Available from: https://www.un.org/womenwatch/daw/beijing/pdf/Beijing\%20 full $\% 20$ report $\% 20$ E.pdf.

[16] African Union Commission. Maputo plan of action 2016 2030 the african union commission. 2016; 0-27. [cited 2021 $\begin{array}{llll}\text { April } & 2] . & \text { Available }\end{array}$ https://au.int/sites/default/files/documents/24099-poa_5_revised_clean.pdf.

[17] WHO. WHO | Global Strategy for Women's, Children's and Adolescent's Health \& Every Woman Every Child Initiative. WHO. 2019. [cited 2021 April 6]. Available from: https://www.who.int/life-course/partners/globalstrategy/en/.

[18] Adedini SA, Mobolaji JW, Alabi M, Fatusi AO. Changes in contraceptive and sexual behaviours among unmarried young people in Nigeria: Evidence from nationally representative surveys. PLoS One. 2021 Feb 2; 16 (2): e0246309.

[19] Bankole A, Adewole IF, Hussain R, Awolude O, Singh S, Akinyemi JO. The incidence of abortion in Nigeria. Int Perspect Sex Reprod Health. 2015; 41 (4): 170-81.

[20] Sageer R, Kongnyuy E, Adebimpe WO, Omosehin O, Ogunsola EA, Sanni B. Causes and contributory factors of maternal mortality: Evidence from maternal and perinatal death surveillance and response in Ogun state, Southwest Nigeria. BMC Pregnancy Childbirth. 2019 Feb 11; 19 (1): 63. doi: https://doi.org/10.1186/s12884-019-2202-1.

[21] Demographic and Health Survey. The Federal Republic of Nigeria Nigeria Demographic and Health Survey 2018 National Population Commission Abuja, Nigeria. 2019.

[22] Yaya S, Bishwajit G. Age at First Sexual Intercourse and Multiple Sexual Partnerships Among Women in Nigeria: A Cross-Sectional Analysis. Front Med. 2018 Jun 8; 5 (JUN): 171. doi: 10.3389/fmed.2018.00171.

[23] Durowade KA, Babatunde OA, Omokanye LO, Elegbede OE, Ayodele LM, Adewoye KR, et al. Early sexual debut: Prevalence and risk factors among secondary school students in Ido-Ekiti, Ekiti state, South-West Nigeria. Afr Health Sci. 2017; 17 (3): 614-22. 
[24] Akumiah P, Suglo J, Sebire S. Early life exposures and risky sexual behaviors among adolescents: A cross-sectional study in Ghana. Niger Med J. 2020; 61 (4): 189-195.

[25] Ekine A. Gender-based violence in primary schools: Nigeria. [cited 2021 Jan 23]. Available from: https://files.eric.ed.gov/fulltext/ED610741.pdf.

[26] David N, Ezechi O, Wapmuk A, Gbajabiamila T, Ohihoin A, Herbertson E, et al. Child sexual abuse and disclosure in south western nigeria: A community based study. Afr Health Sci. 2018; 18 (2): 199-208.

[27] Law Pavilion. The Violence Against Persons (Prohibition) Act, 2015 | The LawPavilion Blog. [cited 2021 Feb 21]. Available from: https://lawpavilion.com/blog/the-violence-againstpersons-prohibition-act-2015/.

[28] Olaoye T, Agbede C. Prevalence and personal predictors of risky sexual behaviour among in-school adolescents in the Ikenne Local Government Area, Ogun State, Nigeria. Int J Adolesc Med Health. 2019. doi 10.1515/ijamh-2019-0135.

[29] Olaleye AO, Obiyan MO, Folayan MO. Factors associated with sexual and reproductive health behaviour of streetinvolved young people: Findings from a baseline survey in Southwest Nigeria. Reprod Health. 2020 Jun 11; 17 (1): 94. doi 10.1186/s12978-020-00937-4.
[30] Adimora GN. Home management of childhood diarrhoea: Need to intensify campaign. Niger J Clin Pract. 14 (2): 237241.

[31] Kassa GM, Degu G, Yitayew M, Misganaw W, Muche M, Demelash T, et al. Risky Sexual Behaviors and Associated Factors among Jiga High School and Preparatory School Students, Amhara Region, Ethiopia. Int Sch Res Not. 2016: 17. doi $10.1155 / 2016 / 4315729$.

[32] Ahinkorah BO. Predictors of modern contraceptive use among adolescent girls and young women in sub-Saharan Africa: a mixed effects multilevel analysis of data from 29 demographic and health surveys. Contracept Reprod Med. 2020; 5 (1): 32. doi https://doi.org/10.1186/s40834-020-00138-1.

[33] United Nations Populations Fund (UNFPA)/Nigeria. Adolescents and Youth Dashboard | UNFPA - United Nations Population Fund. [cited 2021 Mar 12]. Available from: https://www.unfpa.org/data/adolescent-youth/NG.

[34] FP2020. Strategy 2016-2020 | Family Planning 2020. [cited 2020 Feb 8]. Available from: http://www.familyplanning2020.org/strategy.

[35] Markham CM, Tortolero SR, Escobar-Chaves SL, Parcel GS, Harrist R, Addy RC. Family Connectedness and Sexual RiskTaking Among Urban Youth Attending Alternative Hight Schools. Perspect Sex Reprod Health. 2003; 35 (04): 174-9. 